\title{
Performance Analysis of Five Input - Three Output Fuzzy Based Washing Machine
}

\author{
Suchitra ${ }^{1}$, Naveen Kumar Malik ${ }^{2}$ \\ ${ }^{\text {I}}$ (Student, Electronics \& Communication Engineering, Hindu College of Engineering, Sonipat, Haryana India) \\ ${ }^{2}$ (Faculty, Electronics \& Communication Engineering, Hindu College of Engineering, Sonipat, Haryana, India)
}

\begin{abstract}
Now a day, intelligent control of home appliances has rapid market penetration. In this paper, the authors have proposed the design of fuzzy logic controller having five inputs to give correct wash, rinse and spin time of fully automatic machine. The objective is to save a lot of time, electricity and water for washing the cloth. The proposed FLC is simulated using Fuzzy Logic Toolbox of MATLAB. The result is used to calculate the wash time, rinse time and spin time for different type of input conditions. The results are compared with previous washing machine controllers.
\end{abstract}

Keywords: FIS Editor, Fuzzy Logic Controller, MATLAB, Rule Viewer, Surface Viewer

\section{INTRODUCTION}

Washing machine is commonly used household appliances in India. There are two types of washing machines i.e., semi-automatic and fully-automatic. Semi-automatic washing machine consists of two tubes, one for washing and other for drying and rinsing purposes, these machines require manual intervention from washing to drying process. Whereas the fully automatic washing machine have a single tub which serves as the washer, rinse and as well as dryer and only at the start of wash cycle, it require the manual settings which is much less as compare to semi-automatic washing machine. After the start of wash cycle, fully-automatic washing machine, automatically takes the sufficient amount of water and detergent and according to the time set by the user to complete the process of washing and drying.

Electronic appliances manufacturer companies are working on the sensor based fully-automatic washing machines which can sense wash load, water level, type of fabric, type of dirt and dirtiness of clothes to decide the ideal time for washing, number of rinses and spin period as per the information picked by the sensor systems to the machine. The success of sensor based washing machine depends upon the availability of reliable and durable sensors. The presently available sensors for washing machine in the market are load sensor, turbidity sensor, temperature sensor and optical sensor.

The users of washing machines have been facing the problem of selecting the length of wash time based on the type of clothes, type of dirt, dirtiness of clothes and amount of clothes. Most of the people find it very difficult to decide that which cloth needs what amount of washing time. To overcome these problems fullyautomatic washing machines based on fuzzy logic offers the advantage of performance, simplicity and less cost. Fuzzy based washing machine have the sensor based program which checks for the extents of dirt and grease, amount of detergent and water to add which accordingly adjust the wash time, rinse time and spin time.

In this paper, we have introduced five input variables and three output fuzzy logic controller to get correct wash time, rinse time and spin time. Fuzzy logic toolbox in MATLAB is used for FLC simulation. The results so obtained from the fuzzy logic toolbox for the proposed system are compared with the available fuzzy based washing machine.

\section{LITERATURE REVIEW}

Fuzzy Logic: In 1965 the concept of fuzzy logic was first conceived by Professor Lotfi A. Zadeh University of California, Berkeley [1]. Fuzzy logic is powerful design philosophy for describing and developing control systems which provides simple and intuitive method for design engineers to implement complex systems. [2] Fuzzy logic systems allows for an input to exist with varying degree at more than one state at a time and hence allows the engineers to describe the system in more than natural terms [3].

Fuzzy Logic Controller and Its Applications: Fuzzy Controllers, [4] as contrary to classical controllers are capable of utilizing knowledge elicited from human decisions or human operators. Fuzzy Logic Controller for Gas Heater was designed using behavioral modeling and then these modules are connected via structural VHDL to control "Valve Angle." [5]

The fuzzy logic controller for Liquid Level Control was designed using MATLAB for controlling "Valve" and compared with the PID controller. The comparison results show that fuzzy logic controller significantly reduced overshoots and steady state error [9] FLC was designed for an armature control DC motor speed control. VHDL has been used to develop FLC on FPGA. A Sugeno type FLC structure has been used to 
obtain the controller output. The controller algorithm developed synthesized, simulated and implemented on FPGA Spartan 3E xc3s500e-4fg320 [10]

The design and implementation of an autonomous room air cooler using fuzzy rule based control system for the actuators; cooler fan, water pump and room exhaust fan. Three defuzzifiers are used to control MATLAB-simulation is used to achieve the designed goal. [11] Fuzzy logic controller for Water Bath Temperature Control System having two input variables error (E) change of error (DE) and one output variable (U). There are 49 rules used for this system. The computational structure of fuzzy logic control scheme is composed of fuzzification, inference engine and defuzzification. The input to the fuzzy controller is error E (k) and the change in error $\triangle \mathrm{E}(\mathrm{k})$ is computed from the reference output $\mathrm{U}(\mathrm{k})$ based on error and change in error. The execution of simulation was done using the MATLAB simulink tool box. [12]

Fuzzy Logic Controller for Washing machine: In 2007, the Fuzzy Inference is used for determining Wash time. In this design MF used was triangular; the inputs of the Fuzzy Controller were Change of Turbidity and Turbidity, the output was Washing Time. [6] In 2009, Pritesh Lohani, proposed "An improved Controller Microchip for Washing Machine" that comprises of three LIs i.e. Types of Dirt, Dirtiness of Clothes and Mass of Clothes and the LO Wash Time with 25 rules. [8] In 2011, Manish Aggarwal, proposed the Fuzzy Logic Control for Washing Machine having two inputs Type of Dirt and different Degree of Dirt and the output was Wash Time with the inference engine which provides 9 rules for the FLC. The input-output relation is determined by using Fuzzy Interface Unit. [7]

With the above information, a new FLC for Washing Machine is proposed with five inputs and three output variables and 216 rules.

\section{PROPOSED DESIGN}

The proposed Fuzzy Logic Controller for washing machine consists of five Linguistic Inputs i.e.

- $\quad$ Type-of-dirt

- Dirtiness-of-clothes

- Types-of-clothes

- Mass-of clothes

- Temperature

The sensors for all these LIs are also available in the market. All the above LIs control the three LO i.e.

- wash time

- $\quad$ rinse time

- $\quad$ spin time

The proposed Fuzzy Logic Controller inference engine is designed using 216 rules for Wash Time, 216 rules for rinse period and 25 rules for Spin Period. The rules formed in this research are derived from the common sense and purely based on experience from a typical home use. Every Linguistic inputs and outputs has a set of membership functions. The MF used for all LIs and LOs is triangular MF. The X-axis of all the MF graphs represents the LI values which are obtained from the sensors and it ranges from 0 to 1 up to first whereas the Y-axis of all MF graph denotes the degree of membership function which ranges from 0 to 1 .

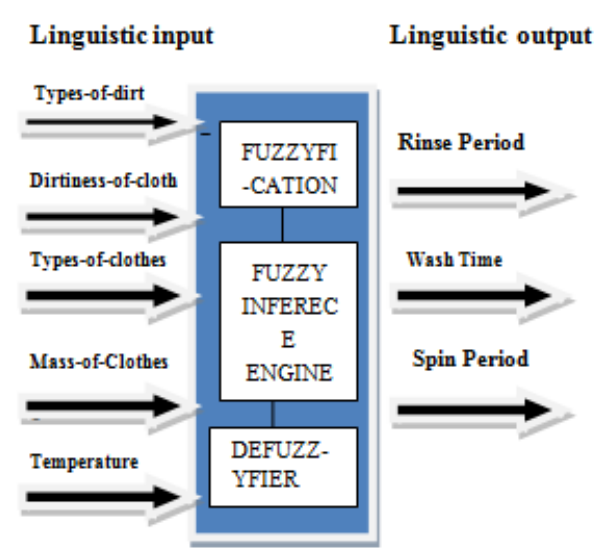

Fig: 1 FLC for Washing Machine

Figure 1 shows the basic approach to the proposed FLC. Fuzzy Logic Controller for Washing Machine consists of mainly three blocks i.e. Fuzzifier, Fuzzy Rule select and defuzzifier. 
Fuzzifier: To deal with the details of fuzzy logic controller, the values for the input and output variables are determined in advanced. There is membership function which is used to map the crisp input values to the fuzzy values and after that suitable operation is applied on them. The process which converts crisp value in fuzzy value is known as fuzzification and fuzzifier is used for performing the fuzzification.

Fuzzy Rule Select: The decisions made by fuzzy logic controller are derived from the rules known as fuzzy rules.

The 216 rules are formed using LIs for LO Wash Time is discussed in terms of IF and THEN statements below:

Rule 1: IF (types of clothes is cotton) and (type of dirt is greasy) and (dirtiness of clothes is large) and (mass of clothes is heavy) and (temperature is hot) THEN wash time is long)

Rule 2: IF (types of clothes are cotton) and (type of dirt is greasy) and (dirtiness of clothes is medium) and (mass of clothes is medium) and (temperature is moderate) THEN (wash time is

Rule 216: IF (types of clothes are woolen) and (type of dirt is not greasy) and (dirtiness of clothes is small) and (mass of clothes is light) and (temperature is cold) THEN (wash time is very short)

All the above discussed rules combined together using MIN-MAX fuzzy inference technique.

Similarly 216 rules for the rinse period can be read using IF and THEN statements:

Rule 1: IF (types of clothe is cotton) and (type of dirt is greasy) and (dirtiness of clothes is large) and (mass of clothes is heavy) and (temperature is hot) then (rinse period is low).

Rule 2: IF (types of clothe is cotton) and (type of dirt is greasy) and (dirtiness of clothes is medium) and (mass of clothes is medium) and (temperature is moderate) then (rinse period is medium).

Rule 216: IF (types of clothe is woolen) and (type of dirt is not greasy) and (dirtiness of clothes is small) and (mass of clothes is light) and (temperature is cold) THEN (rinse period is very low).

All the above discussed rules combined together using MIN-MAX fuzzy inference technique.

Similarly 25 rules for the spin period can be read using IF and THEN statements:

The rules outlined in table 4.6 can be read in terms of IF and THEN statements below:

Rule 1: IF (types of cloth are cotton) and (mass of clothes is heavy) and (temperature is hot) and (atmospheric pressure is low) THEN (spin period is low)

Rule 2: IF (types of cloth are cotton) and (mass of clothes is medium) and (temperature is moderate) and (atmospheric pressure is medium) THEN (spin period is medium)

Rule 25: IF (types of clothes are woolen) and (mass of clothes is light) and (temperature is cold) and (atmospheric pressure is high) THEN (wash time is very high).

Defuzzification: The result obtained from fuzzy inference technique is then processed to produce a quantifiable result i.e. the total time it takes to wash the clothes (Wash Time), it takes to rinse the clothes (Rinse Period) and finally to spin the clothes (Spin Period). Defuzzification process is used to interpret the membership degrees of the fuzzy sets in some specific real value (i.e. in crisp value opposite to that Fuzzification do). Centroid method is used for defuzzification.

\title{
IV. Simulation ANd RESUlts
}

Fuzzy Logic Toolbox is used to create and edit fuzzy inference systems within the framework of MATLAB. Using command line functions the results for different LO's shown below.

\author{
$\mathrm{a}=$ readfis ('washtime.fis') \\ $\mathrm{a}=$ name: 'washtime' \\ type: 'mamdani' \\ andMethod: 'min' \\ orMethod: 'max' \\ defuzzMethod: 'centroid'
}


impMethod: 'min' aggMethod: 'max' input: [1x5 struct] output: [1x1 struct] rule: [1x216 struct] $>>\mathrm{a}=$ readfis('washtime');

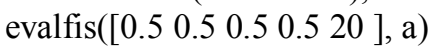
ans $=12.6650$

$>\mathrm{a}=$ readfis('washtime');

evalfis([0.635 245.5 .520$]$, a)

ans $=22.0962$

plotfis(a),

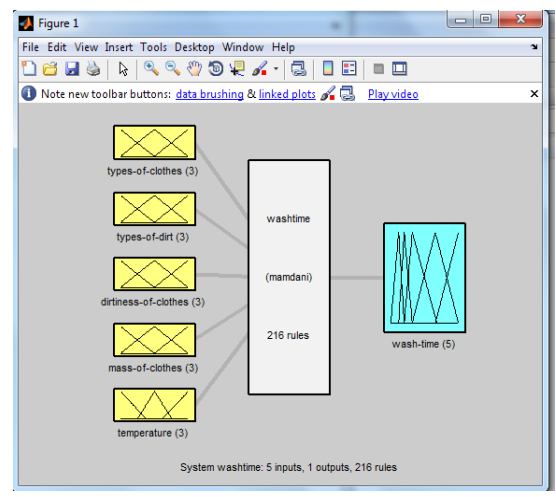

Fig: 2 Fuzzy Logic Controller for Wash Time

Using following commands we obtain the MFs for different LIs and Los plotmf(a,'input',2)

plotmf(a,'input',3)

plotmf(a,'output',1)

$>$ gensurf(a)

$>$ ruleview(a)

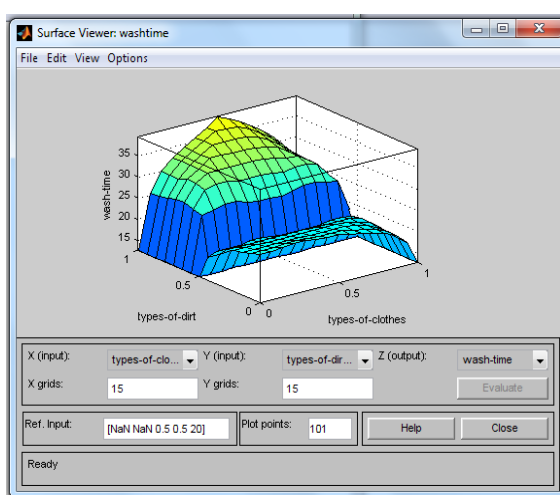

Fig: 3 Surface Viewer for Wash time

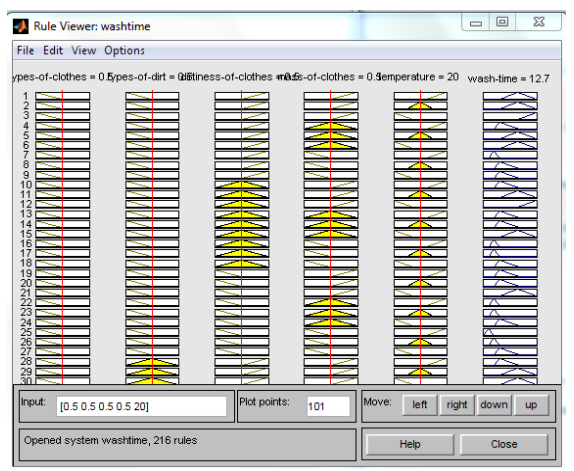

Fig: 4 Rule Viewer For LO Wash Time 


\section{Evaluation Of Real Values On The Bases Of Rules For The Rinse Period}

$\mathrm{a}=$ readfis('rinseperiod.fis')

$\mathrm{a}=$ name: 'rinseperiod'

type: 'mamdani'

and Method: 'min'

or Method: 'max'

defuzz Method: 'centroid'

imp Method: 'min'

agg Method: 'max'

input: [1 1 5 struct]

output: [1x1 struct]

rule: [1x216 struct]

$>\mathrm{a}=$ readfis('rinseperiod');

evalfis([ $\left.\begin{array}{lllll}0.5 & 0.5 & 0.5 & 0.5 & 20\end{array}\right]$, a)

ans $=4.0000$

$>\mathrm{a}=$ readfis('rinseperiod');

evalfis([0.745 0.654 .325 .566 29], a)

ans $=7.8734$

$>>$ ruleview(a)

>>surfview(a)

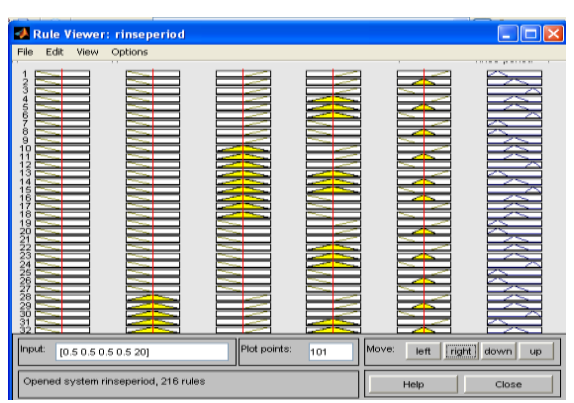

Fig: 5 Rule Viewer for Rinse Period

$>>$ plotfis(a)

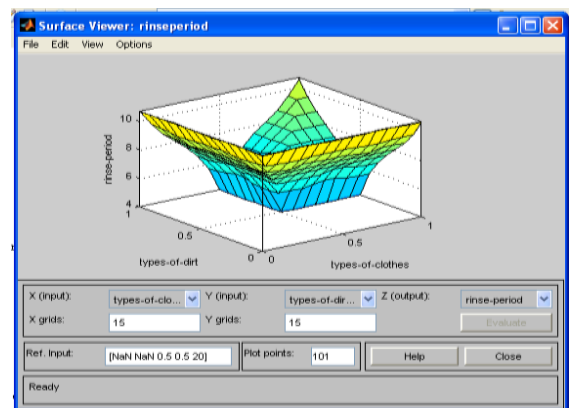

Fig: 6 Surface Viewer for Rinse Period

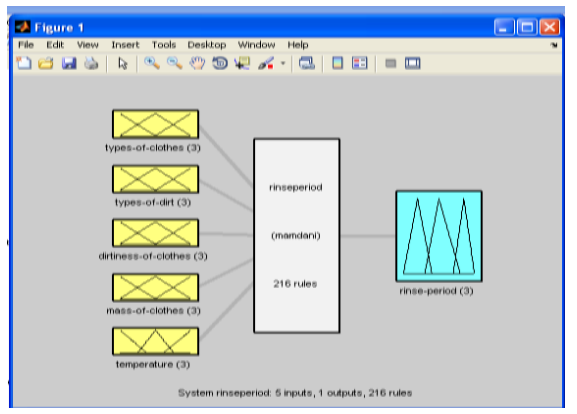

Fig: 7 Fuzzy Logic Controller for LO Rinse Period

\section{Evaluation Of Real Values On The Bases Of Rules For The Spin Period}

$\mathrm{a}=$ readfis('spinperiod.fis')

$\mathrm{a}=$ name: 'spinperiod'

type: 'mamdani'

and Method: 'min' 
or Method: 'max'

defuzz Method: 'centroid'

imp Method: 'min'

agg Method: 'max'

input: [1x4 struct]

output: [1x1 struct]

rule: [1x25 struct]

$\mathrm{a}=$ readfis('spinperiod');

>>evalfis([ $\left.\begin{array}{llll}0.5 & 0.5 & 15 & 0.5\end{array}\right]$, a)

ans $=2.5000$

$\mathrm{a}=$ readfis('spinperiod');

$>>$ evalfis([0.2469 0281336.65 .1781], a)

ans $=0.5502$

$>$ ruleview(a)

$>>$ plotfis(a)

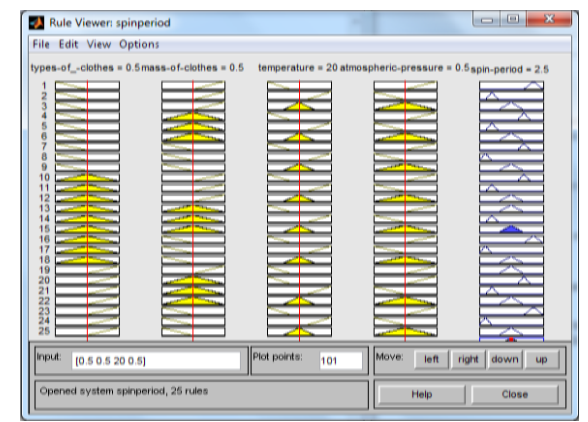

Fig: 8 Rule Viewer for Spin Period

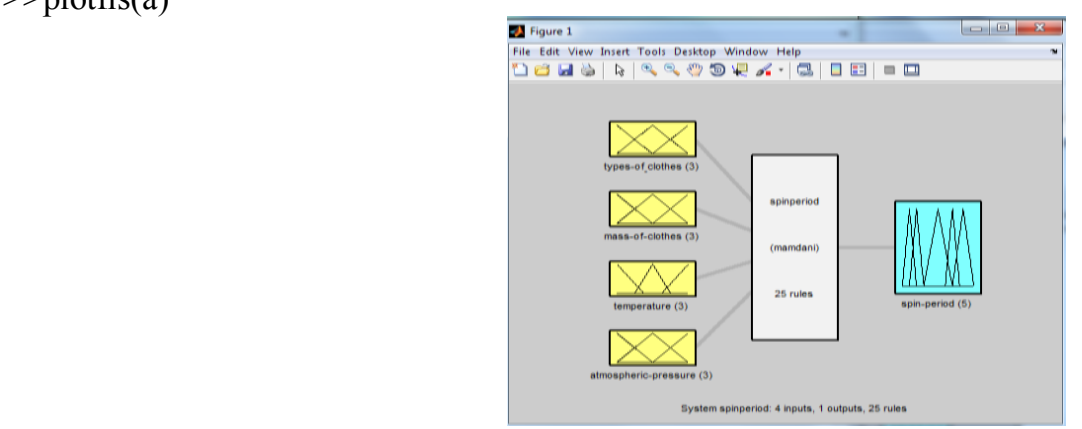

>>surfview(a)

Fig: 9 Fuzzy Logic Controller for Spin period

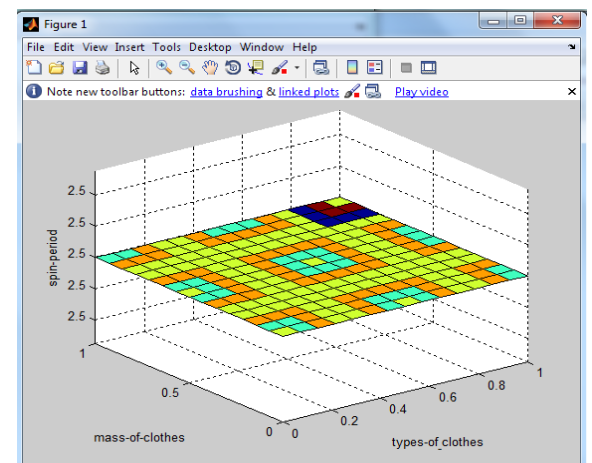

Fig: 10 Surface Viewer for Spin period

V.

Performance Comparison With Previous System

The proposed system is compared with the FLCs for Washing Machine Proposed by Pritesh Lohani in 2009 [12] and Manish Aggarwal in 2011 [9] in terms of electrical energy consumption, time and cost of Wash. 


\begin{tabular}{|c|c|c|c|}
\hline Parameters & $\begin{array}{l}\text { System having two } \\
\text { linguistic input }\end{array}$ & $\begin{array}{c}\text { System having three } \\
\text { linguistic input }\end{array}$ & $\begin{array}{c}\text { System having five } \\
\text { linguistic input }\end{array}$ \\
\hline $\begin{array}{c}\text { Linguistic input Type-of- } \\
\text { Dirt }\end{array}$ & 60 & 60 & 60 \\
\hline $\begin{array}{l}\text { Linguistic Input Dirtiness- } \\
\text { of-Clothes }\end{array}$ & 60 & 60 & 60 \\
\hline $\begin{array}{l}\text { Linguistic Input-Mass-of- } \\
\text { Clothes }\end{array}$ & & 60 & 60 \\
\hline $\begin{array}{l}\text { Linguistic Input Types- } \\
\text { of-Clothes }\end{array}$ & & & 50 \\
\hline $\begin{array}{l}\text { Linguistic Input } \\
\text { Temperature }\end{array}$ & & & 35 \\
\hline $\begin{array}{c}\text { Linguistic Output Wash } \\
\text { Time }\end{array}$ & $30.36 \mathrm{~min}$ & $38.156 \mathrm{~min}$ & $19.616 \mathrm{~min}$ \\
\hline $\begin{array}{l}\text { Energy Consumption } \\
\text { (motor power } \\
\text { consumption=1.1KWH) }\end{array}$ & $\begin{array}{c}(30.36 / 60) * 1.1 \\
=.556\end{array}$ & $\begin{array}{c}(38.156 / 60) * 1.1 \\
=.669\end{array}$ & $\begin{array}{c}(19.616 / 60) * 1.1 \\
=.3596\end{array}$ \\
\hline Cost Per Wash (RS.) & $\begin{array}{c}.556 * 3.70= \\
2.05\end{array}$ & $\begin{array}{c}.669 * 3.70= \\
2.588\end{array}$ & $\begin{array}{c}.3596 * 3.70= \\
1.33\end{array}$ \\
\hline $\begin{array}{l}\text { Cost when five times the } \\
\text { clothes are washed (Rs.) }\end{array}$ & 10.25 & 12.94 & 6.65 \\
\hline \multicolumn{4}{|c|}{ Cost cutting by system $-3=($ cost of system -2$)-($ cost of system -3$)=(12.94-6.65)$} \\
\hline \multicolumn{4}{|c|}{ Saving by proposed system as compare to system-2in single day wash $=6.29 R S$. } \\
\hline Cost cutting by system $-3=$ & t of system-1)-(cost of & $n-3)=(10.25-6.65)$ & \\
\hline Saving by system-3 as col & in $\sin$ & $3.6 \mathrm{RS}$. & \\
\hline
\end{tabular}

Table showing the comparison of proposed FLC with its predecessors.

\section{Conclusion}

By the use of proposed fuzzy logic Controller, we have been able to obtain different Wash Time, Rinse Period, Spin Period (output Variable) for different Type of Dirt, Dirtiness of Clothes, Types of Clothes, Mass of Clothes and Temperature (Input Variable). This situation analysis and comparison has electrical energy and time for washing the clothes by using proposed Washing Machine. This proposed advance and automatic sensor system based Washing Machine depicts the advantage of Fuzzy Logic Controller in the conventional Washing Machine.

\section{REFERENCES}

[1]. L.A. Zadeh, Fuzzy Sets, Information and Control, 338-353, (1965)

[2]. Han H., Chun-Yi and Yury. S, Adaptive Control of a Class of Non-linear Systems with Non-Linearly Parameterized Fuzzy Approximation. IEEE Transactions on Fuzzy Systems, V0l.9, No.2, 315-323, (2001)

[3]. Workman, M. Hardware requirement for Fuzzy Logic Control Systems. Lubbock, TX: Texas Tech University, (1996)

[4]. George J. Kilr and Bo Yuan, Fuzzy Sets and Fuzzy Logic (India: PHI, 1995)

[5]. Sonia Chhabra, VHDL Implementation of Fuzzy Control System, (2006)

[6]. Ge Zhe-Xue, Sun Zhi-Qiang. Neural N/w Theory and the realization MATLAB (Beijing: Electronics industry publishing, 2007)

[7]. Manish Aggarwal, Fuzzy Logic Controller for Washing Machine, IIT Kharagpur (2011)

[8]. Lohani P., and Hasan,S.R..Design of an Improved Controller Microchip For Washing Machine, $16^{\text {th }}$ Annual Electronics New Zealand Conference (pp. 20-26).Dunedin : Otago University (2009)

[9]. Dharamniwas, Aziz Ahmad, Varun Redhu and Umesh Gupta, Liquid Level Control by Using Fuzzy Logic Controller, International Journal of Advances in Engineering \& Technology, (July 2012). ISSN: 2231-1963

[10]. Mani Shankar Anand \& Barjeev Tyagi, Design and Implementation of Fuzzy Controller on FPGA, I.J. Intelligent Systems and Applications, 10, 35-42 Published Online in September MECS (www.mecs-press.org) (2012)

[11]. M. Abbas, M. Saleem Khan, Fareeha Zafar, Autonomous Room Air Cooler Using Fuzzy Logic Control System, International Journal of Scientific \& Engineering Research Volume 2, Issue 5, (May-2011)

[12]. Om Prakash Verma and Himanshu Gupta, Fuzzy Logic Based Water Bath Temperature Control System, International Journal of Advanced Research in Computer Science and Software Engineering, Volume 2, Issue 4, (April 2012) 